\title{
Hepatitis A in Travelers: The European Experience
}

Robert Steffen

\author{
Division of Epidemiolog. and Prevention of Communicable Diseases. \\ Institure for Social and Preventive Medicine, \\ Zurich University, Zurich. Switzerland
}

\begin{abstract}
Each year $\sim 14$ million Europeans travel to developing countries in Africa, Asia, and Latin American as well as to infrequently visited countries in eastern Europe. Without protection, travelers develop symptomatic hepatitis $A$ at the rate of 3 cases per 1000 people per month of stay. Those who eat and drink under poor hygienic conditions have an even higher risk, $20 / 1000 /$ month. Studies show that hepatitis $A$ is the most frequent vaccine-preventable disease in travelers to developing countries. Immunity to hepatitis A virus is infrequent among northern European travelers, except for those born before 1945, with a history of jaundice, or who lived for $>1$ year in a developing country.
\end{abstract}

Only a few decades ago, "turning yellow . . . was taken as part of the adventure" by expatriates, as recollected by General Norman Schwarzkopf [1]. Travelers today, however, increasingly demand full health during and after a trip, and therefore, an evaluation of the risk of hepatitis $A$ in this population is essential. Ideally, this should be based on the following data: the incidence rate of symptomatic infection in unprotected travelers, the proportion of anti-hepatitis $A$ virus (HAV) antibody-negative travelers, and the impact of the infection, particularly the case-fatality rate.

Unfortunately, there is a paucity of up-to-date concise data on the subject, and only a few studies have correlated the number of cases with the number of travelers to various regions of the world. Further compounding the problem is that important details, such as the duration of stay abroad and the immune status of travelers, were not documented or only incompletely documented. Studies report attack rates per stay abroad rather than incidence rates per time period. Nevertheless, it is possible to estimate that the average duration of stay abroad is $\sim 1$ month. Although data are limited and often out-of-date, I provide here some basic estimates of the risk of hepatitis in European travelers.

\section{Population at Risk}

Each year $\sim 14$ million Europeans visit developing countries where hepatitis $\mathrm{A}$ is highly endemic, predominantly Africa (4 million), Asia ( 7 million), and Central and South America ( 2 million). About $80 \%$ of these travelers are tourists, with the remainder consisting of business persons, students, foreign aid volunteers, and other professionals and their families. Another risk group, but one of lower magni-

Reprints or correspondence: Prof. R. Steffen. ISPM. Sumatrastrasse 30. CH-8006 Zurich. Switzerland.

The Journal of Infectious Diseases 1995;171(Suppl 1):S24-8

(c) 1995 by The University of Chicago. All rights reserved.

0022-1899/95/7ISI-0006\$01.00 tude, is the 70 million northern Europeans who visit and spend time in southern Europe.

Older seroprevalence surveys indicated that a major proportion of adult travelers were protected by anti-HAV antibodies, and much of the approach to this problem was based on those findings. However, the demographic data were based on the immune status of blood donors [2]. Since the majority of donors generally belong to lower socioeconomic classes than the traveling population, a higher proportion of anti-HAV-positive persons is to be expected. Data from recent studies [3-5] that concentrated on travelers and excluded persons with a history of jaundice or who stayed in developing countries for prolonged times suggest that the prevalence rate of anti-HAV antibody among persons born after 1945 in Germany and Switzerland is very low, definitely below $20 \%$ (figure 1 ).

\section{Risk during International Travel}

Since the arrival of techniques to differentiate hepatitis A from other types of hepatitis, a single retrospective study has analyzed in detail the risk of travelers importing symptomatic hepatitis. Investigators in this Swiss study [6] asked all laboratories in the Zurich area able to identify anti-HAV IgM to report all positive cases from 1977 to 1981 . In the 137 cases of imported hepatitis reported, 78 were HAV infections. Case details were determined by reviewing hospital charts and asking physicians who had requested the laboratory test to fill out a questionnaire (table 1) [6]. Investigators estimated that $\sim 50 \%$ of all HAV cases were missed (unpublished data); some cases were diagnosed and treated abroad, samples in all cases were not submitted for serotyping, and sera were analyzed by laboratories outside the catchment area. In addition, the study could not identify asymptomatic infections. At a time when only hepatitis A and B could be differentiated, more than half of all cases of hepatitis imported from developing countries were clearly diagnosed as hepatitis $A$. This infection accounted for $\sim 60 \%$ of hepatitis cases in travelers returning from Africa, Latin America, or 
Figure 1. Seroprevalence before departure of anti-HAV in German and Swiss travelers [3-5]. *History of jaundice or stay in developing country $>1$ year.

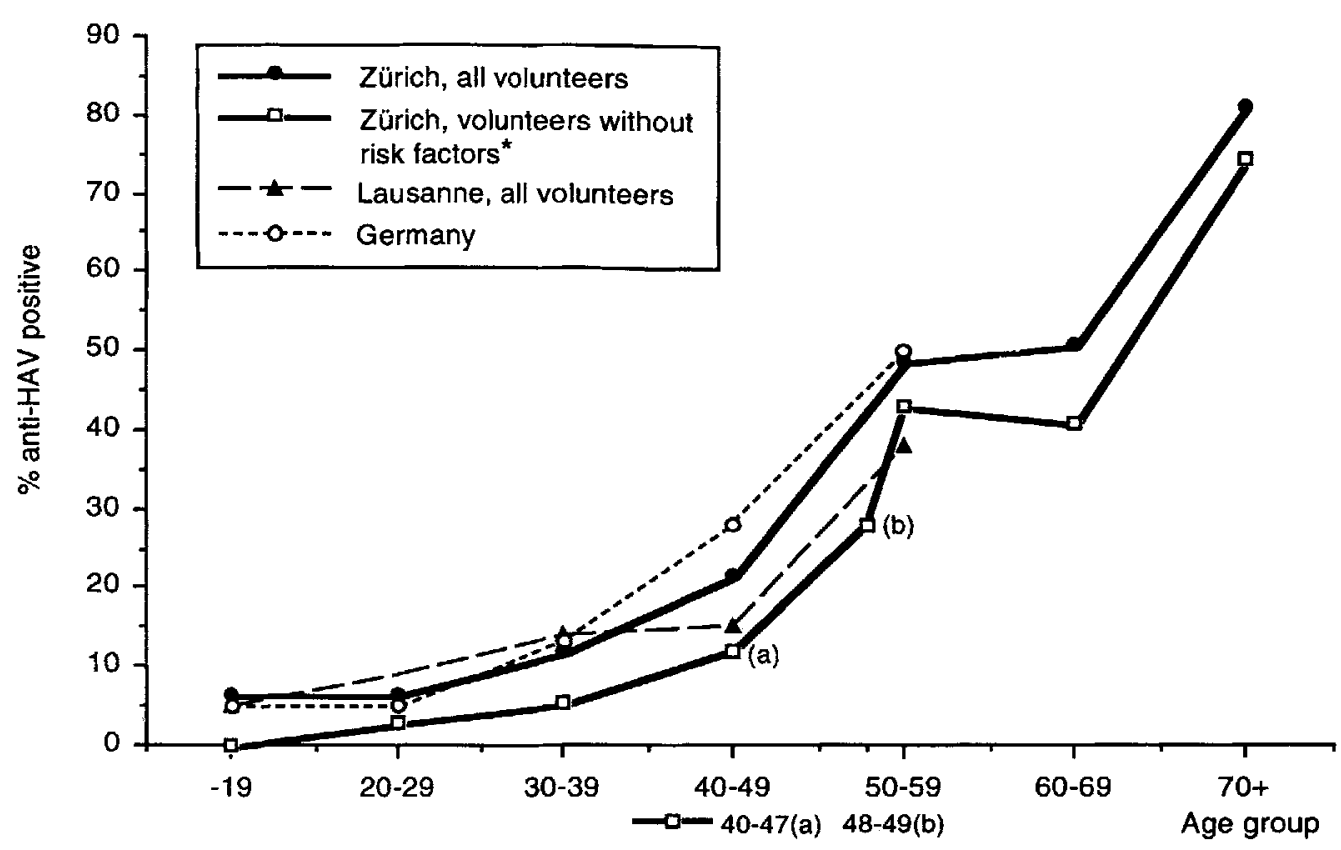

south and Southeast Asia [6]. Trampers (e.g., hitchhikers through India) had a much higher risk than other travelers. Hepatitis $B$ and non-A, non-B hepatitis were each diagnosed in $\sim 15 \%$ of the cases, and almost $10 \%$ remained unclassified. In contrast, hepatitis A played only a minor role in infections acquired within Europe.

Obviously, various biases are inherent in such a retrospective study. Nevertheless, it appears that between various developing regions of the world, there was no marked difference in attack rates for hepatitis A (table 1); in contrast, rates were much lower in travelers to southern Europe. Although the endemicity of hepatitis $A$ in southern Europe has substantially decreased since World War II, rates are still higher than in other industrialized areas.

How do findings from this study compare with those from

Table 1. Hepatitis A attack rate in Swiss travelers at various destinations, 1977-1981 $(n=78)$.

$\left.\begin{array}{lc}\hline \text { Destination } & \begin{array}{c}\text { Attack rate/1000 } \\ \text { journeys }\end{array} \\ \hline \text { Northern Europe } & 0.2 \\ \text { North America } & 0 \\ \text { Southern Europe } & 1.5 \\ \text { North Africa } & 62 \\ \text { Subsaharan Africa } & 125 \\ \text { Near East } & 45 \\ \text { Middle East } & 181 \\ \text { Far East } & 55 \\ \text { Central America } & 83 \\ \text { South America } & 67\end{array}\right\}$

NOTE. From [6].

* Average. older studies that analyzed either all cases of imported hepatitis or only imported non-B hepatitis? Table 2 shows similar results from Swiss [6, 7] and Danish studies [8]; however, the rates were markedly lower than both Swedish surveys $[9,10]$, despite the fact that the latter did not include hepatitis $B$ cases. A partial explanation is that in comparison with other populations, Swedish residents have the lowest prevalence of anti-HAV antibody [2]. It is also possible that a larger proportion of Swedish travelers went abroad to work and thus stayed for a prolonged time. A British study showed markedly lower attack rates; however, findings were qualified by the fact that "only a fraction of those who contracted hepatitis A" were examined [11].

In the only follow-up epidemiologic study of hepatitis in travelers, 8 of almost 8000 visitors to developing countries were diagnosed with symptomatic hepatitis A [12]. The majority were tourists who had stayed in hotels, often high-class accommodations. The mean duration of incapacity to work was $\sim 1$ month. Nine travelers had non-A, non-B hepatitis, some of whom may have had pyrimethamine-sulfadoxineinduced toxic hepatitis, and 2 professionals contracted hepatitis $B$ while working in the tropics. Although the number of patients is small, some observations were possible. The average duration of the stay abroad was 19 days. Thus, the estimated case incidence rate per month (cases/persons/month) was $1.6 / 1000 /$ month. Since $\sim 40 \%$ of travelers are anti$\mathrm{HAV}$-positive by either infection or administration of immune serum globulin (ISG) (unpublished data), the corrected case rate for unprotected travelers is $\sim 3 / 1000 /$ month. Asymptomatic infections were disregarded in the preceding calculations [12].

French investigators studied hepatitis A seroconversion in 233 volunteers working in the bush of central or West Africa 
Table 2. Imported hepatitis (any serotype) attack rate per journey abroad.

\begin{tabular}{|c|c|c|c|c|c|}
\hline \multirow[b]{2}{*}{$\begin{array}{l}\text { Imported } \\
\text { from }\end{array}$} & \multicolumn{5}{|c|}{ Imported to } \\
\hline & $\begin{array}{c}\text { Zurich [7] } \\
(n=221) \\
1971-1976\end{array}$ & $\begin{array}{c}\text { Copenhagen }[8] \\
(n=105) \\
1976-1978\end{array}$ & $\begin{array}{c}\text { Zurich [6] } \\
(n=137) \\
1977-1981\end{array}$ & $\begin{array}{c}\text { Göteborg }[10] \\
(n=80) \\
1980\end{array}$ & $\begin{array}{c}\text { Stockholm [9] } \\
\qquad \begin{array}{c}n=65) \\
1982\end{array}\end{array}$ \\
\hline Northern Furope & 0.6 & 0.5 & 1 & NA & NA \\
\hline Southern Europe & 10 & 3 & 4 & 20 & 5 \\
\hline North Africa & 100 & 50 & 60 & 140 & 190 \\
\hline $\begin{array}{l}\text { Other developing } \\
\text { countries }\end{array}$ & $60-290$ & 80 & 110 & 860 & 830 \\
\hline Trampers & 2000 & NA & NA & NA & NA \\
\hline
\end{tabular}

NOTE. NA, not available.

from 1979 to 1980 [13]. In this group, $125(54 \%)$ were antiHAV-positive before departure; the remaining 108 who were anti-HAV-negative received no ISG during their stay. The seroconversion rate was $19 / 1000 /$ month, with most affected patients developing jaundice.

Data from all available retrospective, follow-up, and seroconversion studies lead to the conclusion that symptomatic hepatitis $\mathrm{A}$ develops in unprotected, nonimmune travelers who journey from industrialized countries to developing regions and stay for $\geqslant 1$ month, at a rate of $3 / 1000 /$ month. High rates also apply to short-term vacationers and business persons staying in good, even four- or five-star, hotels. Among trampers and other persons who eat and drink under poor hygienic conditions, the incidence rate increases sixfold. Conversely, the rate is at least 50 times lower (i.e., $0.05-0.1 / 1000 /$ month) in travelers who stay in southern Europe $[7,14]$. Nobody thus far has assessed the incidence rate of hepatitis $\mathrm{A}$ in nonimmune visitors to eastern Europe, but considering that these are high-endemicity countries, the risk at least in remote areas may be considered as high.

\section{Impact of Hepatitis A on Travelers}

Adults with hepatitis $A$ are incapacitated for an average of 4-10 weeks, with the length of illness associated with age [12]. A survey of airline crews showed that pilots (who are usually older) were incapacitated for significantly longer periods than younger cabin crew members (Gutersohn T, personal communication). Children tolerate the infection better and recover more rapidly; the case-fatality rate is very low compared with that in adults. However, particularly nonimmune immigrant children visiting the home countries of their parents are in close contact with native children and thus at high risk of contracting HAV infection. Whether symptomatic or asymptomatic, they may spread the infection at home or in day care centers [14]. For many years, the case-fatality rate in adults has been underestimated; it may be $>2 \%$ in older persons $[15,16]$.

\section{Impact of Imported Hepatitis A on the Community}

Today, a large proportion of cases of hepatitis A in industrialized countries relates to the large number of travelers [17]. The proportion may differ from one year to the next because of regional epidemics in drug addicts. This, in turn, leads to a statistical decrease in the proportion of cases in travelers. Lax notification procedures may also contribute to variations, depending on the level of awareness. An explanation of the particularly high proportion of cases of imported hepatitis in Switzerland is that $12 \%$ of the population visited a developing country in 1991 [18].

\section{Morbidity and Mortality}

Symptomatic hepatitis A clearly is the most frequently occurring vaccine-preventable infection in travelers (figure 2). In many areas of the world, the risk of HAV infection is comparable to that of malaria among travelers who do not use chemoprophylaxis. Although hepatitis B has lower incidence rates, mortality estimates are of the same order of magnitude as in hepatitis A [15, 16, 19]. American and European data, however, suggest that hepatitis $B$ is rare in vacationers [20]. The risk of hepatitis $A$ in unprotected travelers to usual destinations is 100 times higher than for typhoid fever and 1000 times higher than for cholera (reviewed in [21]). Like hepatitis $\mathrm{A}$, these two gastrointestinal infections have a low case-fatality rate: $\leqslant 2 \%$ in recent statistical evaluations.

\section{Impact of Active Vaccine Use}

In January 1992, an active vaccine against hepatitis A was introduced in Switzerland and has been well received. Preliminary data indicate an annual reduction by $15 \%$ in cases of imported hepatitis $A$, and this trend is thought to be due to active immunization of the majority of Swiss travelers [16]. Today, ISG is often refused. To date, no cases of serious side effects or vaccine failure have been reported in $\sim 500,000$ doses given to travelers in Switzerland. 


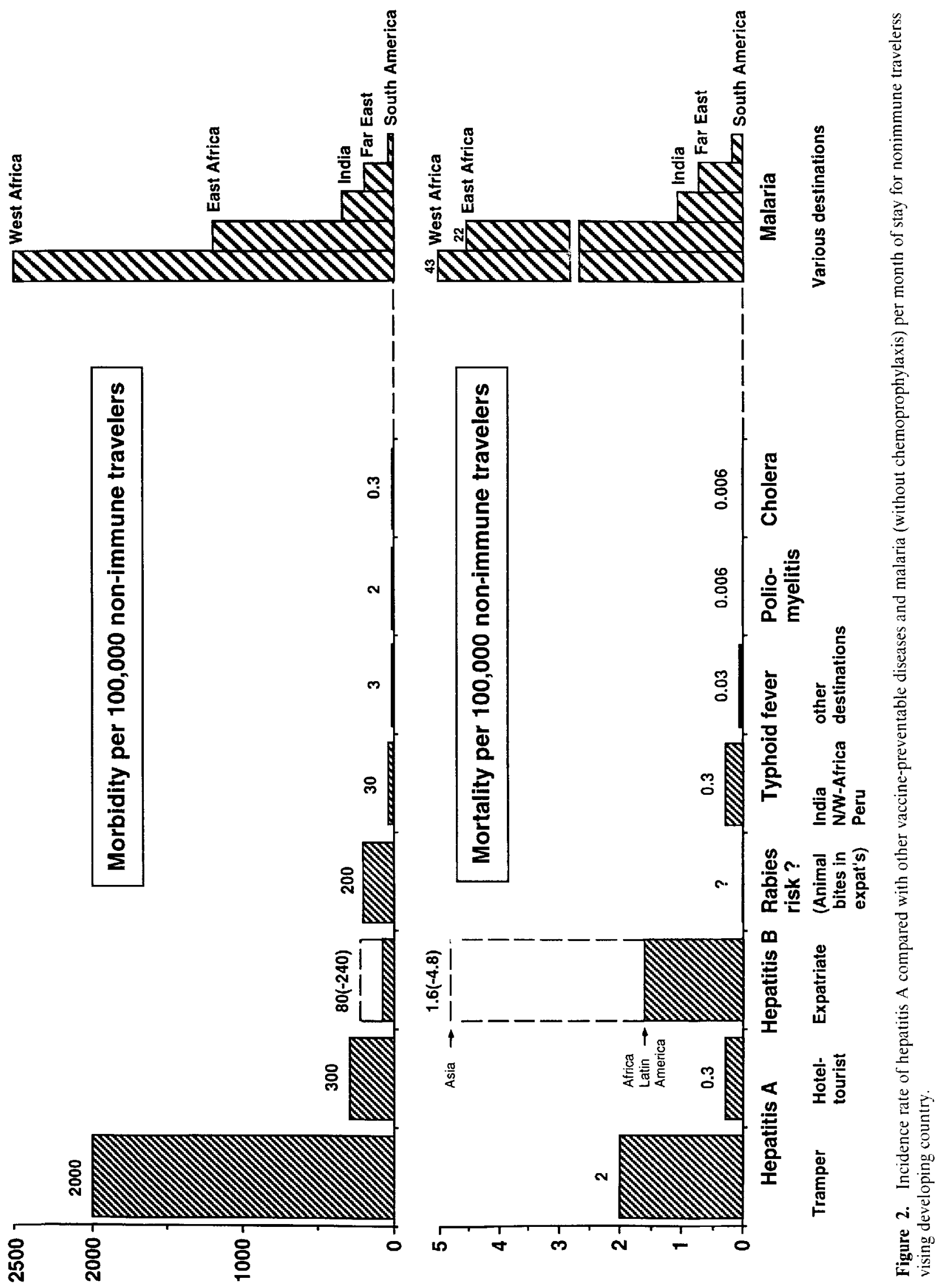




\section{Conclusion}

The European experience illustrates that hepatitis $A$ is an important health risk for travelers residing in industrialized nations and visiting developing countries, particularly since most are now susceptible to the infection. Travelers' hepatitis A has an important impact both on the individual. because of incapacitation lasting several weeks and a substantial case-fatality rate in older adults, and on the community, since a large proportion of these infections are imported.

\section{References}

I. Schwarzkopf NH. Petre P. It doesn't take a hero. New York: Linda Gray Bantam, 1993:33.

2. Frösner GC. Papaevangelou G, Butler R, et al. Antibody against hepatitis $A$ in seven European countries. Am J Epidemiol 1979: 1 10:63-9.

3. Studer S. Joller-Jemelka HI. Steffen R, Grob PJ. Prevalence of hepatitis A antibodies in Swiss travellers. Eur J Epidemiol 1993;9:50-4.

4. Wagner $G$. Hepatite $A$ : des immunoglobulines au vaccin. Medecine et Hygiene 1991:49:3198-201.

5. Bienzle U, Bock HL, Meister W, Clemens R, Kruppenbacher JP. AntiHAV seroprevalence and hepatitis $A$ vaccination in immune subjects [letter]. Lancet 1993;341:1028.

6. Apothéloz M. Grob PJ. Steffen R. Schär M. Welchen Auslandreisenden ist ein Impfschutz gegen Hepatitis zu empfehlen? Soz Praventivmed 1982:27:264-5.

7. Steffen R, Regli P, Grob PH. Wie gross ist das Risiko einer Reisehepatitis? Schweiz Med Wochenschr 1977; 107:1300-7.

8. Skinhøj P. Glund C. Ramso K. Travelers hepatitis. Scand J Infect Dis $1981: 13: 1-4$.
9. Iwarson S, Wahl M. Hepatitis A in Swedish foreign travellers. Dev Biol Stand 1983:54:419-22.

10. Christenson B. Epidemiological aspects of acute viral hepatitis $A$ in Swedish travellers to endemic areas. Scand J Infect Dis 1985; 17:510.

11. Hall SM, Mortimer PP. Vandervelde EM. Hepatitis A in the traveler [letter]. Lancet 1983:2:1198.

12. Steffen R. Rickenbach M. Wilhelm U. Helminger A, Schär M. Health problems after travel to developing countries. I Infect Dis 1987; 156:84-91.

13. Larouzé B, Gaudebout C, Mercier E, et al. Infection with hepatitis A and $B$ viruses in French volunteers working in tropical Africa. Am J Epidemiol 1987; 126:31-7.

14. Christenson B. Epidemiology of hepatitis A in children in Sweden 1979-1983. Scand J Infect Dis 1986; 18:281-5.

15. Forbes A, Williams R. Increasing age-an important adverse prognostic factor in hepatitis A virus infection. $J$ R Coll Physicians Lond $1988 ; 22: 237-9$

16. Steffen R, Kane MA, Shapiro CN, Billo N, Schoellhorn KJ, van Damme $P$. Epidemiology and prevention of hepatitis $A$ in travelers JAMA 1994:272:885-9.

17. Steffen R. Risk of hepatitis A in travellers. Vaccine 1992;10:69-72.

18. Bundesamt für Statistik. Der Reiseverkehr der Schweizer im Ausland: Internationaler Reiseverkehr und Grenzübertritte der Schweizerinnen und Schweizer 1992. Bern, Switzerland: Bundesamt für Statistik, 1993.

19. Immunization Practices Advisory Committee. Hepatitis B virus: a comprehensive strategy for eliminating transmission in the United States through universal childhood vaccination. MMWR Morb Mortal Wkly Rep 1991;40:1-19.

20. Steffen R. Risk of hepatitis B for travelers. Vaccine 1990;8:3l-2.

21. Steffen R. Travel medicine-prevention based on epidemiological data. Trans R Soc Trop Med Hyg 1990; 85: 156-62. 